\title{
Development and evaluation of a real-time PCR assay for the detection of Acarapis woodi (tracheal mites) in Apis mellifera
}

\author{
Catia Delmiglio ${ }^{1}$, Qing Hai FAN ${ }^{1}$, Sherly George ${ }^{1}$, Lisa WARD ${ }^{1}$, Giles Budge ${ }^{2}$, \\ Alan FLYNN ${ }^{1}$, Lalith KUMARASINGHE ${ }^{1}$ \\ ${ }^{1}$ Plant Health and Environment Laboratory, Ministry for Primary Industries, P.O. Box 2095, Auckland 1140, New \\ Zealand \\ ${ }^{2}$ Fera, Sand Hutton, York YO41 1LZ, UK
}

Received 3 May 2015 - Revised 9 November 2015 - Accepted 26 November 2015

\begin{abstract}
The tracheal mite, Acarapis woodi, is an obligate endoparasite of honeybees and a regulated pest in countries where these mites are absent. This work describes the development of a real-time PCR method for detecting tracheal mites in honeybees. The real-time PCR was evaluated for specificity, sensitivity and speed to $\operatorname{detect} A$. wood $i$, compared to the standard manual thoracic disc method (TDM). The assay detected $A$. woodi down to a $1 \%$ incidence level in bees and 1000 copies of the target DNA when using plasmid standards. Initial testing showed no cross-reaction with the other two Acarapis species from different geographical regions or with other species of mites associated with bees. However, during extensive testing of bees, a rare population of Acarapis externus mite was identified that did cross-react with the assay. Despite this cross-reaction, the assay has been shown to be a useful screening tool and results are reliable if the TDM is used as a backup to screen hives where a positive signal is obtained.
\end{abstract}

honeybee / tracheal bee mite / Acarapis / automated DNA extraction / real-time PCR

\section{INTRODUCTION}

Honeybees, Apis mellifera L., are afflicted by a variety of pests and diseases including several arthropod parasites (Evans et al. 2007; Pettis and Pankiw 1998). Tracheal mites, Acarapis woodi Rennie (Acari:Tarsonemidae), are obligate endoparasites of honeybees, and heavy mite infestations may cause reduction in bee activity and may be a contributing factor to colony losses, although the exact causes of loss of colonies infested with $A$. woodi are still unknown (Sammataro et al. 2013). Tracheal mites are found in most areas where there are honeybees with the exception of

Corresponding author: C. Delmiglio, Catia.Delmiglio@mpi.govt.nz

Manuscript editor: Peter Rosenkranz
Australia, New Zealand and Scandinavia (CAPCO 1992; Denmark et al. 2000). The tracheal mite colonises the bee's tracheal system; they pierce the tracheal walls and feed on the haemolymph (Pettis and Pankiw 1998; SchimdHempel 1998). Mites are not generally found outside of the bee in infested colonies with the exception of mated females which migrate out of the trachea to find new bee hosts. If other mites move out of the host, they seem to be unable to regain access to the bee and will die as a result (Pettis and Pankiw 1998).

The presence of tracheal mites in beehives can affect colony survival and can lead to a reduction in pollen collection and honey production (Pettis and Pankiw 1998; Schmid-Hempel 1998). The small size of the mites $(\sim 120-190 \mu \mathrm{m})$ and location within the bee's trachea pose a challenge for diagnostic identification, and this has led to 
misdiagnoses of infestation (Evans et al. 2007). Detailed assessment of low levels of mite infestations involves microscopic examination of the bee's tracheae. The thoracic disc method (TDM), which involves cutting a thoracic disc containing the prothoracic trachea for slide mounting and microscopic observations, is the conventional diagnostic method used in the surveillance programme for detection of tracheal mites in New Zealand.

As tracheal mites are not present in New Zealand, a national apiculture surveillance programme is carried out annually by the Ministry for Primary Industries (MPI) to affirm the absence of this parasite. A trained worker examines approximately 350 bees per day, and around 85,000 bees are dissected by up to five full-time technical staffs during each surveillance season. However, the TDM is repetitive and requires a high level of skill and concentration from laboratory staff. Due to the repetitiveness of the method, there is high risk of worker fatigue, which may inadvertently lead to a failure to detect mites. This paper describes the work done to develop a molecular method of sufficient sensitivity and specificity to enable screening for $A$. woodi in the New Zealand national survey for exotic pests, with the aim of eventually replacing the TDM for bee surveillance in New Zealand. Part of this method has already been described in Sammataro et al. (2013) but the full method is now presented here.

\section{MATERIAL AND METHODS}

\subsection{Biological material}

Bees infested with $A$. woodi were sourced from Dr. G. E. Budge (Fera, York, UK), Dr. J. McMullan (Trinity College, Dublin, Ireland) and from Mr. M. Kempers (Ontario Beekeeper's Association, Canada). Bees infested with Acarapis externus or A. dorsalis were sourced from Mr. L. I. de Guzman (US Department of Agriculture, CA, USA). New Zealand's A. externus and A. dorsalis mites and other mite species including Macrocheles sp. (Acari:Macrochelidae), family Rhodacaridae (Acari), Melittiphis sp. (Acari:Laelapidae), Varroa destructor (Acari:Varroidae), Parasitus sp. (Acari:Laelapidae), Pneumolaelaps sp. (Acari:Parasitidae),
Neocypholaelaps sp. (Acari:Amerosiidae) and Cryptostigmata mites (mixture of species) were supplied from MPI's Plant Health and Environment Laboratory (PHEL; Auckland, New Zealand) collection. All specimens were stored in $70 \%$ ethanol prior to use.

\subsection{DNA extraction from individual mites}

DNA was extracted from single or multiple mites of the same species as described by Navajas et al. (1996). Briefly, individual mites were ground in a $0.5-\mathrm{mL}$ micro-centrifuge tube using a micro-tube pestle prior to adding $40 \mu \mathrm{L}$ of $50 \%(w / v)$ Chelex ${ }^{\mathbb{B}} 100$ Resin (1421253, BioRad Laboratories, Hercules, CA, USA). The tube was then incubated for at $95{ }^{\circ} \mathrm{C}$ for $5 \mathrm{~min}$ and then centrifuged for $1 \mathrm{~min}$ at $8000 \mathrm{~g}$ to pellet the resin. The supernatant was transferred to a new microcentrifuge tube and used for subsequent PCR reactions. DNA was also extracted from individual $A$. wood $i$ mites or from bee's trachea using Prep GEM $^{\mathrm{TM}}$ (PIN0500, ZyGEM NZ Ltd., Hamilton, New Zealand), following the manufacturer's instructions.

When a non-destructive method was necessary, DNA was extracted using a modification of the method described by Zheng et al. (2002) for nematodes. Briefly, using a sterile pin, individual mites were placed into 0.2-mL PCR tubes containing $8 \mu \mathrm{L}$ of extraction buffer (Zheng et al. 2002) and $2 \mu \mathrm{L}$ of proteinase $\mathrm{K}(600 \mu \mathrm{g} /$ mL) (P2308, Sigma-Aldrich Pty Ltd., Sydney, Australia). Each tube was incubated in a thermocycler (ThermoMixer C, Eppendorf, Hamburg, Germany) at $65^{\circ} \mathrm{C}$ for $1 \mathrm{~h}$ followed by $95^{\circ} \mathrm{C}$ for $10 \mathrm{~min}$ and finally $2 \mathrm{~min}$ at $15^{\circ} \mathrm{C}$ to cool the solution. Each mite exoskeleton was retrieved out of the solution and mounted on a slide for later morphological identification if necessary. The remaining solution without the mite was then used directly in PCR $(2 \mu \mathrm{L}$ per reaction).

\subsection{DNA extraction from bees}

Prior to DNA extraction, 100 bees were washed as follows. The bees were placed in a jar containing warm water and shaken in an orbital mixer for 20 min prior to transfer to a stack of three Endicott sieves (1680/600/ $250 \mu \mathrm{m}$ ), where they were washed with tepid running water for $15 \mathrm{~min}$ to dislodge any mites on their bodies. Dislodged mites were collected from the bottom $(250 \mu \mathrm{m})$ sieve, and the washed bees were then used for nucleic acid extraction. This washing method is part 
of the routine process for screening bees during the New Zealand annual national survey for exotic pests and allows for the screening of exotic mites in bee washings (Dr. S. George, personal communications).

DNA was extracted from cleared lysate using a KingFisher $^{\mathbb{B}} \mathrm{mL}$ Magnetic Particle Processor system (Thermo Fisher Scientific Inc., Hudson, NH, USA) and using buffers and magnetic beads supplied in an InviMag ${ }^{\circledR}$ DNA Mini Kit (1437100300, Invitek GmbH, Berlin, Germany) using the protocol and programme recommended by Invitek $\mathrm{GmbH}$ and Thermo Fisher Scientific Inc., respectively. Briefly, washed bees were prepared for DNA extraction by removing the abdomen of each bee using a clean scalpel and placing the bee heads and thoraxes into filter grinding bags (420100, Bioreba AG, Reinach, Switzerland). Lysis buffer P from the kit was added to the grinding bag at a rate of $0.5 \mathrm{~mL}$ buffer per bee. The bees were ground to a lysate using a semi-automated HOMEX 6 homogeniser (Bioreba AG, Reinach, Switzerland). Lysate $(600 \mu \mathrm{L})$ was decanted into a clean micro-centrifuge tube, and $30 \mu \mathrm{L}$ of proteinase $\mathrm{K}$ was added as per the manufacturer's protocol. The lysate was incubated at $65{ }^{\circ} \mathrm{C}$ for $30 \mathrm{~min}$ in a thermocycler (ThermoMixer C, Eppendorf, Hamburg, Germany) prior to centrifugation at $8000 \mathrm{~g}$ for $1 \mathrm{~min}$ to pellet debris. The cleared lysate $(420 \mu \mathrm{L})$ was then used in the extraction as per the manufacturer's protocol.

\subsection{Conventional PCR amplification of cytochrome oxidase I gene and sequencing}

The mitochondrial cytochrome oxidase I gene (COI) was amplified for $A$. woodi, A. externus and $A$. dorsalis using the primers AcwdCOI F and AcwdCOI R and the PCR conditions published by Evans et al. (2007). The $\sim 380$-bp amplified fragments were excised from the gel and purified using a Quantum Prep ${ }^{\mathbb{B}}$ Freeze ' $n$ ' squeeze DNA gel extraction column (732-6165, BioRad Laboratories, Hercules, CA, USA) following the manufacturer's instructions. The purified product was cloned using an Invitrogen ${ }^{\mathrm{TM}} \mathrm{TOPO}^{\mathbb{B}}$ TA Coning Kit with One Shot $^{\mathbb{B}}$ TOP10 Chemically Competent Escherichia coli (K45001, Thermo Fisher Scientific Inc., Hudson, NH, USA) following the manufacturer's protocols. At least three clones per sample were sequenced in both directions (Ecogene ${ }^{\circledR}$ Ltd., Auckland, New Zealand). Sequences obtained in this study were submitted to GenBank $A$ woodi accessions FJ603294 and
FJ603296 (UK) and GQ916565 (Canada); A. externus accessions FJ603293, GQ916566, HQ162653, HQ162659 to HQ162661 and HQ243440 to HQ243442 (New Zealand) and GQ916566 (USA); and $A$. dorsalis accessions GQ916567 and GQ916568 (USA) and GQ916568 and HQ243433 to HQ243439 (New Zealand).

\subsection{Real-time primer design for the detection of $A$. wood $i$}

Sequences obtained for the COI region from A. woodi (Canada and UK), A. externus (New Zealand and USA) and $A$. dorsalis (New Zealand and USA) were aligned with an $A$. woodi COI sequence from the USA (GenBank accession EU190886 from Evans et al. 2007), using MEGA v4 (Tamura et al. 2007). A forward (aw_F1-flap) and reverse (aw_R3) primer and a Locked ${\text { Nucleic } \text { Acid }^{\text {TM }} \text { (LNA) substituted TaqMan }}^{\circledR}$ probe (aw_LNAProbe) were designed to be specific for A. woodi using Beacon Designer ${ }^{\mathrm{TM}}$ v7.5 (PREMIER Biosoft, Palo Alto, CA, USA) (Table I). All the primers and probes were assessed for specificity using the Basic Local Alignment Search Tool (BLAST), and their thermodynamics were investigated using Oligo Analyzer 3.1 (Integrated DNA Technologies Inc., Coralville, IA, USA). The fluorogenic probe was modified at the 3 ' end with Black Hole Quencher 1 (BHQ1; Sigma-Aldrich Pty Ltd., Sydney, Australia) and at the $5^{\prime}$ end with the reporter dye 6-carboxyfluorescein (6-FAM; SigmaAldrich Pty Ltd., Sydney, Australia). The forward primer was modified with the inclusion of a 5' AT-rich flap (Afonina et al. 2007).

\subsection{Real-time PCR}

PCR reaction conditions for the $A$. woodi real-time primers were optimised (data not shown), and all subsequent real-time reactions were run in final volume of $10 \mu \mathrm{L}$. Each reaction contained PCR core reagents from the Invitrogen ${ }^{\mathrm{TM}}$ Platinum ${ }^{\circledR}$ Quantitative PCR SuperMix-Uracil-DNA Glycosylase (UDG) (11730017, Thermo Fisher Scientific Inc., Hudson, $\mathrm{NH}$, USA) containing a total of $3.5 \mathrm{mM}$ of $\mathrm{Mg}$, $0.3 \mu \mathrm{g}$ of bovine serum albumin (BSA) (B6917, Sigma-Aldrich, Sydney, Australia) and $1 \mu \mathrm{L}$ of target DNA per reaction. Primers and probe were used at final concentrations of 300 and $100 \mathrm{nM}$, respectively. Tubes were cycled at $50^{\circ} \mathrm{C}$ for $2 \mathrm{~min}$ (UDG incubation), $95^{\circ} \mathrm{C}$ 
Table I. Sequence of primers and probes used for the detection of Acarapis woodi (based on COI region) and the generic detection of Acarapis spp. (based on ITS2 region).

\begin{tabular}{llcc}
\hline $\begin{array}{l}\text { Primer/probe } \\
\text { name }\end{array}$ & Sequence 5'-3' & $\begin{array}{l}\text { Amplicon } \\
\text { length }\end{array}$ & Region \\
\hline aw_F1-flap & $\begin{array}{l}\text { AATAAATCATAATGATATCCCAATTATCTGAGTAATG } \\
\text { aw_R3 }\end{array}$ & 113 bp & COI \\
aw_LNAProbe & 6-FAM-ACC[+T]GT[+C]AA[+T]CC[+A]CCTAC-BHQ1 & & \\
TMite_F1 & GCCATAAGACATCACTCGACTATTCT & 94 bp & ITS2 \\
TMite_R1 & TCATTTAAACTTCATGATACTCTCAATCAG & & \\
TMite_Probe & 6-FAM-TGCGCAATGCAACTAGTCCTCTAAAG & & \\
& ACTAGTTC-BHQ1 & & \\
\hline
\end{tabular}

Areas of sequences in bold are non-complementary flaps; $[+]=$ locked nucleic acid bases

for 2 min and 35 cycles (extended to 40 for validation tests) of $95^{\circ} \mathrm{C}$ for $10 \mathrm{~s}$ followed by $59^{\circ} \mathrm{C}$ for $45 \mathrm{~s}$ within a BioRad CFX (BioRad Laboratories, Hercules, CA, USA). Real-time data was collected and analysed according to the manufacturer's software instructions.

The PCR competency and success of nucleic acid extractions were assessed using two internal control assays which amplify part of the 18S rRNA gene of A. mellifera (Ward et al. 2007a) and the internal transcribed spacer (ITS) 2 of Acarapis species (see Table I for primer/probe sequences). The internal control assays were set up and cycled as described for the $A$. woodi assay.

\subsection{Evaluating the specificity and sensitivity of the $A$. wood $i$ real-time assay}

The $A$. woodi real-time PCR assay was evaluated for specificity to $A$. woodi by testing with DNA from individual mites of $A$. woodi (UK and Canada), $A$. externus (USA and New Zealand) and $A$. dorsalis (USA and New Zealand). The assay was also tested with DNA extracted from 15 bees bulked together from each of the following: bees known to be infected with $A$. woodi (UK and Canada), bees without tracheal mites but known to have $A$. externus mites present on their bodies (New Zealand) and bees without tracheal mites but known to have high number of $A$. dorsalis present on their bodies (USA). The presence of the mites in each case was confirmed by microscopic examination of the trachea, neck and the dorsal grooves.

The $A$. woodi real-time PCR assay was also tested for cross-reaction with DNA isolated from individual mites or a mix of mites obtained from bee washings as follows:
Macrocheles sp. (Acari:Macrochelidae), family Rhodacaridae (Acari), Melittiphis sp. (Acari:Laelapidae), V. destructor (Acari:Varroidae), Parasitus sp. (Acari:Laelapidae), Pneumolaelaps sp. (Acari:Parasitidae), Neocypholaelaps sp. (Acari:Amerosiidae) and Cryptostigmata mites (mixture of species). The assay's specificity and sensitivity were tested using plasmid standards for all three Acarapis species with 10 to $10^{7}$ copies of the 380 -bp amplicon for the COI gene (Evans et al. 2007). The plasmid DNA had been diluted in DNA extracted from healthy bees (no tracheal mites) to account for any inhibitory compounds present in the standard bee extracts.

\subsection{Bulking experiments}

In order to determine the maximum number of bees that could be bulked but still allow the detection of a single $A$. woodi-infected bee, one bee infected with tracheal mites was bulked with healthy bees (no tracheal mites) at the following bulking ratios: 1:5, 1:10, 1:15, $1: 20,1: 25$ and 1:33. Each bulking ratio was repeated three times. The PCR competencies of the DNA extracts were tested using the bee $18 \mathrm{~S}$ internal control real-time assay described earlier and with the $A$. woodi real-time assay to see if $A$. woodi DNA could be successfully detected.

An experiment was then performed using the optimal bulking ratio determined (1:15), with the single infected bee categorised according to the numbers of mites observed in their trachea when examined under the microscope. The categories were as follows: low level of infection $(<10$ mites per bee), medium level of infection ( $>10-50$ mites per bee) and high level of 
infection ( $>50$ mites per bee). Each category was repeated three times. The DNA extracts were then tested using the $A$. woodi and bee $18 \mathrm{~S}$ internal control realtime PCR assays to see if $A$. woodi DNA could be successfully detected.

\subsection{Validation of the $A$. woodi real-time assay using laboratory blind panels}

In order to validate the $A$. woodi real-time assay, randomised 'blind' panels were prepared for testing. The blind panels were set up by the PHEL annual bee surveillance coordinator and passed to a PHEL scientist to complete extraction and PCR testing. The scientist doing the testing was not aware of the percentage of $A$. woodi $i$ infected bees in each sample within each panel.

Five blind panels were set up, each blind panel consisted of four samples with each sample containing 100 bees; this is the maximum number of bees tested per hive for the annual national survey for exotic pests in New Zealand. A total of 2000 bees were tested over five blind panels.

Each sample within each panel was prepared by mixing healthy bees (no tracheal mites) with bees known to be infected with a high number of tracheal mites $(>50$ mites per bee). Five different levels of infection were prepared as follows: 0 (all healthy bees), 2 (98 healthy bees and 2 bees infected with tracheal mites), 5,10 and $15 \%$. The four samples in each panel represented one of the infection rates and with at least one of the samples in each panel being $0 \%$ infection to act as a negative control. The percentage infection tested across the five panels was randomised (see Table II for details).

For the sample setup, the heads and thoraxes of infected bees were mixed with the heads and thoraxes of healthy bees prior to DNA extraction. DNA was extracted from a 100 bee sample by randomly bulking the bees into 6 replicates of 15 bees and 1 replicate of 10 bees; as such, it was not known which of the 7 replicates in each sample contained the infected bees. DNA extraction and real-time PCR were carried out as described previously.

\subsection{Validation of the $A$. woodi real-time assay using field samples}

Although A. woodi is not present in New Zealand, the specificity and reliability of the real-time assay was tested with field samples collected as part of the annual national survey for exotic pests. The test was run alongside the standard manual TDM over two seasons, 2010 and 2011. In 2010, 4200 bees were collected from 69 apiaries (80 hives). In 2011, 2100 bees were collected from 18 apiaries (21 hives). Bees were bulked, and DNA was extracted and tested by real-time PCR as described previously.

\subsection{Additional work done to determine the source of positive real-time signals}

During 2011 and 2012, four experiments were done to determine the source of positive signals obtained from real-time testing of New Zealand's national surveillance samples (described above). For the experiments, bees were collected from two hives from which a positive real-time signal had been obtained in 2010 and 2011, bees from one hive were used for experiments 1 to 3 and bees from the second hive were used for experiment 4. For all bees collected, the abdomen of each bee was removed and discarded. All DNA extractions were done as bulks of 15 (or 10 for last bulk where appropriate). Extractions were done as previously described unless stated. All extractions were tested by real-time PCR as previously described. The four experiments are described below.

1. Heads and thoraxes of 420 bees were separated. A modification to the extraction method was that the 15 heads were extracted in $2.5-\mathrm{mL}$ buffer and the 15 thoraxes in 5 -mL buffer due to weight differences.

2. The heads and thoraxes of 105 bees were separated, but this time, care was taken to ensure the neck was kept with the head.

3. Heads and thoraxes of 105 bees were separated, but this time, the bee's air sacs and tracheae were removed from the thorax and care was taken to ensure that the neck remained attached to the thorax. The removed tracheae were bulked together, and DNA was extracted from these and tested by real-time PCR as described. DNA was also extracted from individual air sacs as follows. Each air sac was placed in $10 \mu \mathrm{L}$ of DEPC-treated water and boiled for $10 \mathrm{~min}$, and then, $2 \mu \mathrm{L}$ of the boiled extract was used directly in the real-time PCR.

4. A total of 388 Acarapis mites were removed after screening the neck area of approximately 1000 bees. DNA was extracted from each single mite using a non-destructive method modified from 
Table II. Validation test results for five blind panels.

\begin{tabular}{|c|c|c|c|c|}
\hline & Sample 1 & Sample 2 & Sample 3 & Sample 4 \\
\hline \multicolumn{5}{|l|}{ Panel 1} \\
\hline Infection rate & $5 \%$ & $0 \%$ & $15 \%$ & $10 \%$ \\
\hline Final results & Positive (4/7) & Negative $(0 / 7)$ & Positive (7/7) & Positive (5/7) \\
\hline \multicolumn{5}{|l|}{ Panel 2} \\
\hline Infection rate & $0 \%$ & $2 \%$ & $15 \%$ & $5 \%$ \\
\hline Final results & Negative $(0 / 7)$ & Positive (2/7) & Positive (7/7) & Positive (5/7) \\
\hline \multicolumn{5}{|l|}{ Panel 3} \\
\hline Infection rate & $10 \%$ & $0 \%$ & $2 \%$ & $15 \%$ \\
\hline Final results & Positive (6/7) & Negative $(0 / 7)$ & Positive (2/7) & Positive (6/7) \\
\hline \multicolumn{5}{|l|}{ Panel 4} \\
\hline Infection rate & $5 \%$ & $10 \%$ & $15 \%$ & $0 \%$ \\
\hline Final results & Positive (3/7) & Positive (6/7) & Positive (7/7) & Negative $(0 / 7)$ \\
\hline \multicolumn{5}{|l|}{ Panel 5} \\
\hline Infection rate & $1 \%$ & $0 \%$ & $5 \%$ & $0 \%$ \\
\hline Final results & $(1 / 7)$ & Negative $(0 / 7)$ & Positive (2/7) & Negative $(0 / 7)$ \\
\hline
\end{tabular}

Each panel consisted of four samples (each sample containing 100 bees). The number of tracheal mite-infested bees added to each sample is shown as the infection rate (e.g. $5 \%=5$ infested bees and 95 healthy bees). Each sample of 100 bees was bulked into seven replicates $(6 \times 15$ and $1 \times 10)$. Final results show the number of replicates testing positive out of seven. Key positive $=C_{q}<35$ and negative $=C_{q} \geq 35$

Zheng et al. (2002). Each mite exoskeleton was retrieved out of the solution and mounted on a slide for morphological identification, and $2 \mu \mathrm{L}$ of the remaining solution was used directly in PCR. Each DNA extraction was checked for PCR competency with the internal control real-time PCR designed to the Acarapis ITS2 region (Table I). Morphological identification was only done if the corresponding DNA extract gave a positive signal in the $A$. wood $i$ real-time PCR.

\section{RESULTS}

\subsection{Evaluation of the specificity of the $A$. woodi real-time assay}

Real-time primers and a probe for $A$. woodi were designed within a single variable region of the COI sequence obtained (Figure 1).

Using the $A$. woodi real-time assay, $A$. woodi DNA was successfully amplified from individual mites from two geographical locations, Canada and the UK. When the assay was initially tested against DNA from individual, or multiple mites of A. externus (from USA and New Zealand) and A. dorsalis (from USA and New Zealand), no amplification was observed. No cross-reaction was observed with DNA extracted from other mite species collected from bee washes as follows: Macrocheles sp. (Acari:Macrochelidae), members of the family Rhodacaridae (Acari), Melittiphis sp. (Acari:Laelapidae), Varroa destructor (Acari:Varroidae), Parasitus sp. (Acari:Laelapidae), Pneumolaelaps sp. (Acari:Parasitidae), Neocypholaelaps sp. (Acari:Amerosiidae) and Cryptostigmata mites (mixture of species).

When the assay was tested on bee DNA, likewise, initial tests showed no cross-reaction with DNA extracted from healthy New Zealand bees (no tracheal mites), which were known to have A. externus and/or A. dorsalis on their bodies. When the assay was used on bulked samples of 


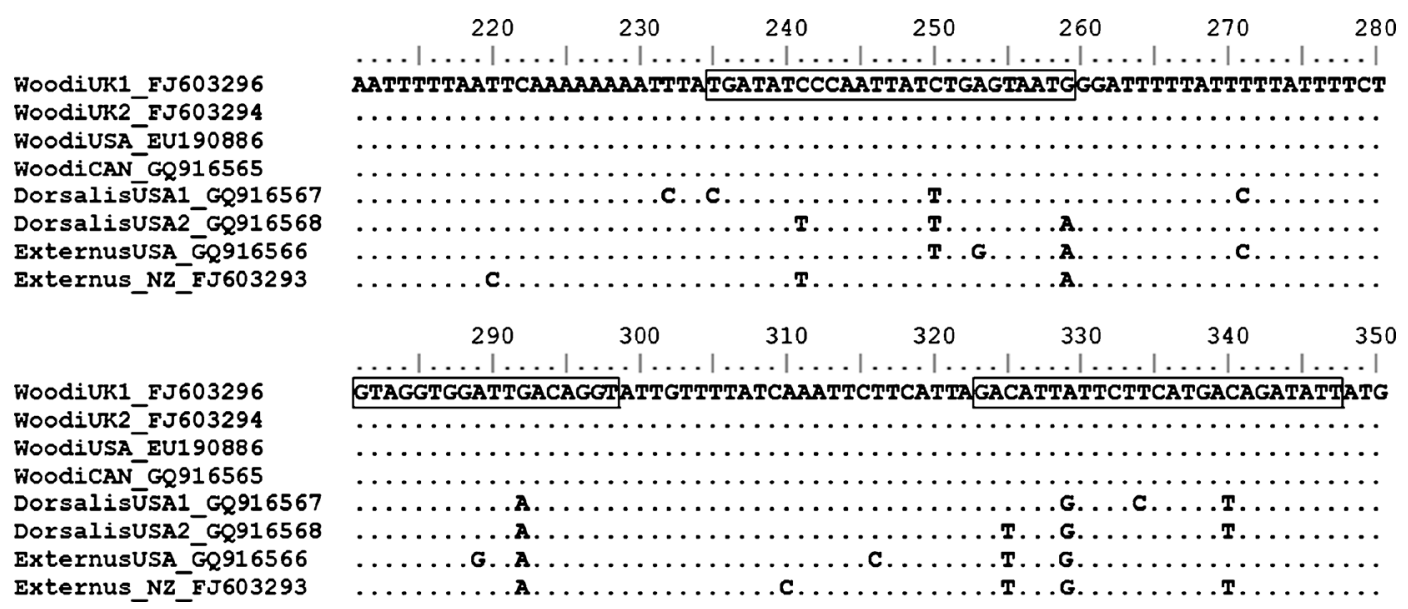

Figure 1. View of part of the multiple alignments of all unique Acarapis sequences for the COI gene. The boxed regions show the position of the forward primer (nucleotide position 235-239); the reverse primer (nucleotide position 323-347) and probe (nucleotide position 281-290). Only polymorphic nucleotides are shown. Dot indicates an identical nucleotide at that position.

bees from the USA known to be very heavily infested by $A$. externus and/or A. dorsalis, a low level of cross-reaction was observed above 35 PCR cycles; to overcome this, the cycling condition of the $A$. wood $i$ real-time assay reaction was reduced from 40 to 35 cycles. At 35 cycles, amplification was not observed in the real-time test when the plasmid DNA for these species was used in sensitivity tests at concentrations up to $10^{7}$ copies, but $A$. woodi plasmid DNA was reliably detected down to 1000 copies (Figure 2).

\subsection{Experiments to determine the maximum bulking rate for bees}

The maximum number of bees that could be bulked to allow consistent detection of a single A. woodi-infected bee was found to be 15 . $A$. woodi could be detected at all bulking rates below 15; however, above this rate, detection became inconsistent (e.g. amplification occurred in only one or two of the three replicates). Bulking rates above 15 bees were considered too unreliable to be used with the selected nucleic acid extraction method.

Using the optimal bulking rate of 15 bees, the detection of 1 infected bee in 14 healthy bees was determined using three different levels of $A$. woodi infection, categorised as low (1-10 mites per bee), medium $(>10-50$ mites per bee) or high ( $>50$ mites per bee). All infection levels of $A$. woodi were successfully detected by real-time PCR $\left(C_{q}\right.$ values ranging from 26 for the highinfection category to 32 for the lowinfection category).

\subsection{Validation of the $A$. woodi real-time assay using blind panels}

The $A$. woodi real-time assay was validated against five blind panels. Table II summarises the panels and results obtained. The $A$. woodi real-time assay was able to successfully detect $A$. woodi in all samples to which tracheal miteinfected bees had been added. The numbers of positive replicates increased as the number of infected bees spiked into the 100 sample increased. No amplification was observed in the healthy control samples.

\subsection{Validation of the $A$. woodi real-time assay using field samples}

Although the majority of DNA extractions from bees collected during the national 


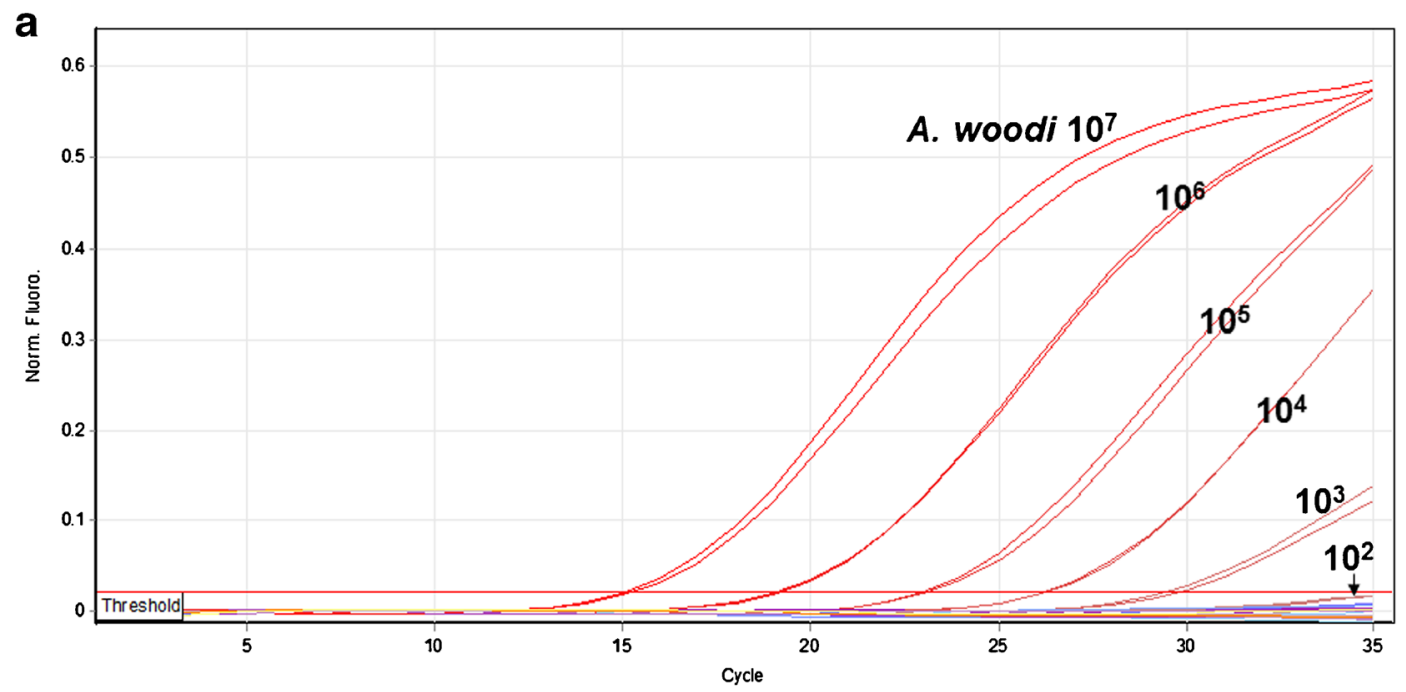

b

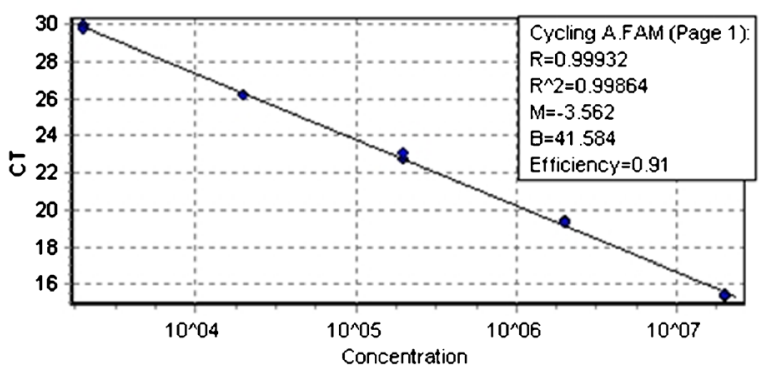

Figure 2. a View of the results from the real-time PCR reaction of Acarapis woodi (red lines), A. externus (blue lines ) and $A$. dorsalis (yellow lines ) plasmid DNA standards (100-10 $7^{7}$ copies), showing that only $A$. woodi DNA was amplified. b Graph showing the best fit line for the amplification of the $A$. woodi plasmid DNA standards.

surveillance programme were tested negative for A. woodi, positive amplification signals were obtained for some DNA extractions across both years. In 2010, positive amplification was detected in 7 out of 80 hives tested ( $\sim 9 \%$ of hives) covering 69 apiaries ( $\sim 10 \%$ of apiaries) and in 2011 from 2 of 21 hives tested ( $\sim 10 \%$ of hives) covering 18 apiaries ( $\sim 11 \%$ of apiaries), and both had given a positive result in 2010. Of the seven DNA extractions tested by real-time from each positive hive (i.e. 100 bees per hive with 7 bulks of 15 or 10 bees), only around one to two DNA extracts gave a positive signal, suggesting an infection incidence of $1-2 \%$ for each positive hive (i.e. 1 or 2 bees per 100 bees). Cycling threshold values $(C q)$ for all positive results by the quantitative PCR (qPCR) ranged from 30 to 33, suggesting a low level of mite infection of each bee.
In both years, thorough checks were done using the TDM to determine whether there may be a low level of $A$. woodi infestation in these hives; however, no tracheal mites were found.

\subsubsection{Identification of source of cross- reaction in field samples}

Further work was done to determine whether positive reactions observed from field samples were due to contamination, or cross-reaction, or whether $A$. wood $i$ was actually present at very low levels in the hives but was not detected using the TDM. Contamination was ruled out by retesting DNA extractions with fresh reagents. Crossreaction with other Acarapis species or other mites was checked by amplifying and sequencing a larger area of the COI gene (Evans et al. 2007) 
from the positive DNA extracts. In all cases, sequence matched $99-100 \%$ to $A$. wood $i$ sequences in GenBank.

A number of experiments were done to determine the source of the positive signals during real-time PCR. In the first experiment where bee heads and thoraxes were tested separately, the results obtained were not conclusive. Positive real-time signals were obtained from both head and thorax DNA extractions. It was possible that there was variation with respect to whether the neck area (which was likely to harbour Acarapis mites) remained with the head or thorax when separated. In the second experiment, care was taken to keep the neck with the thorax and air sacs and tracheae were totally removed. In this experiment, only the thorax extractions gave a positive real-time signal. DNA extractions from the heads, air sacs and the tracheae were all negative. This results suggest that the positive signal could not have come from infested trachea but most likely to have come from the neck area. In the third experiment, when care was taken to keep the neck with the head, positive reactions were obtained from head extractions, only confirming that the neck was definitely the source of the positive signals. In the fourth experiment, of the 388 single-mite extractions tested, only 139 gave an ITS signal. Of these 139 successful extractions, 2 gave a positive signal with the $A$. woodi assay $(\sim 1.4 \%$ of mites tested). Extraction success was low $(35.8 \%)$ due to the very small size of the mites and difficulties working with them.

The DNA extracts which gave positive signals by qPCR were also amplified by conventional PCR (Evans et al. (2007) primers); both PCR products were sequenced and showed $99 \%$ nucleotide identify to $A$. woodi sequences in GenBank.

The mites corresponding to the two positive DNA extractions were identified morphologically, and photographs were taken as a record. One of the mounted specimens was not from a mature developmental stage and therefore not suitable for identification. The other specimen was clearly identified as A. externus (Figure 3c).

\section{DISCUSSION}

Detection of tracheal mites currently relies on physical examination of bees by dissection and microscopy, and in New Zealand, the TDM is adopted in its national surveillance programme. The TDM is a technique developed for the detailed assessment of mite infestation and allows detection of low levels of infestation (below $5 \%$ ), but it is very laborious. Symptoms of tracheal mite infestations in bees, such as crawlers in front of the colonies, are not reliable indicators of mite infestations in the field as they are similar to those caused by some viral infections and nosemosis (Sammataro et al. 2013). Screening of tracheae from many bees bulked together (e.g. by grinding thoraxes of many bees in liquid and then look for the mites in the suspension) have been developed but are not suitable to detect low level of infestation (Sammataro et al. 2013). Guanine visualisation and enzyme-linked immunosorbent assay (ELISA) are other methods developed for the detection of tracheal mites, but these methods have limitations in their applications and are not generally recommended as low levels of infestations may go undetected (Sammataro et al. 2013). Until recently, there have been no PCR-based methods for specific detection of $A$. woodi; the primers published by Evans et al. (2007) have been shown to amplify other Acarapis species as well as other mites commonly found on honeybees (this study, data not shown). Kojima et al. (2011) published a conventional PCR method shown to amplify $A$. woodi DNA and not A. externus, but this method has not been tested on A. dorsalis DNA. Although their test was able to detect $A$. wood $i$ when four mites were present in a single bee, it was not able to detect the presence of a single mite unless a nested PCR was performed (Kojima et al. 2011). In addition, the sensitivity of detection at different bulking rates for extractions was not determined. Realtime PCR has been used previously for detection of insects (Burgher-MacLellan et al. 2009; Kox et al. 2005; Yu et al. 2005) and for specific detection of honeybee pests and diseases (Celle et al. 2008; Chantawannakul et al. 2006; Chen et al. 2009; Ward et al. 2007a, b). Automated DNA extraction combined with real-time PCR has 


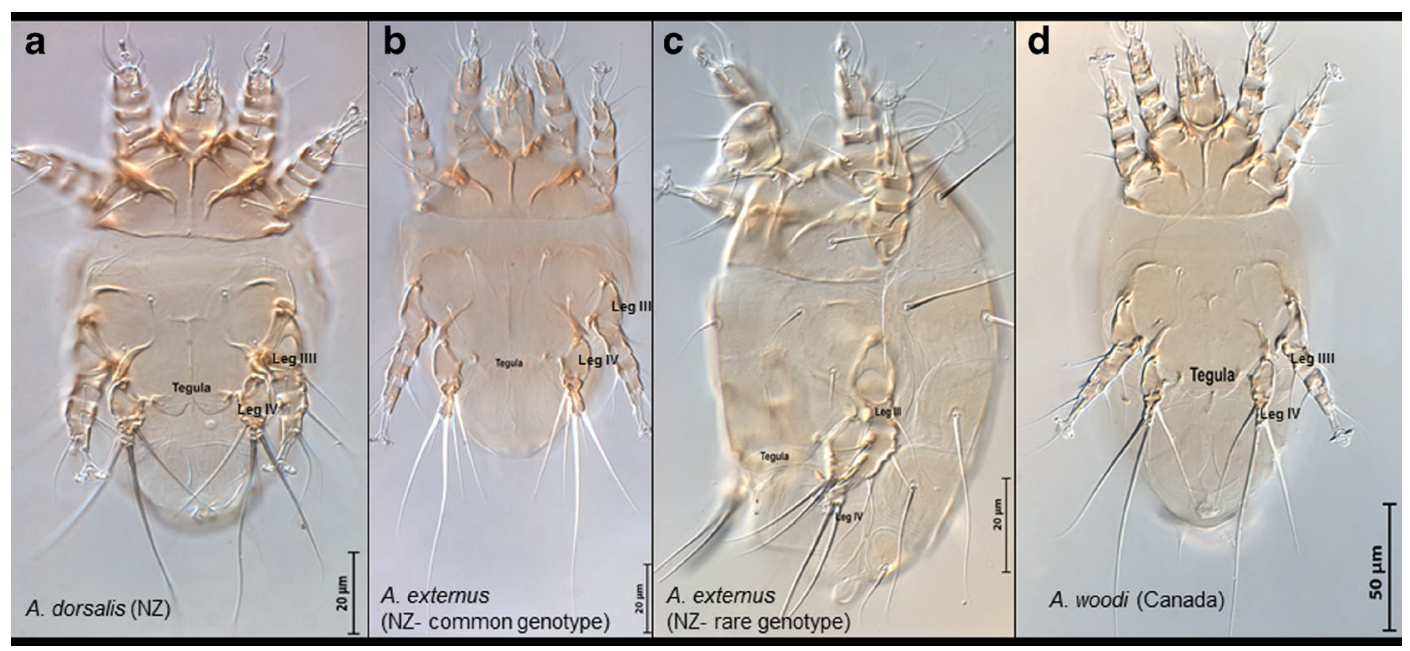

Figure 3. Ventral view of a Acarapis dorsalis from New Zealand, b A. externus from New Zealand (most common genotype), c A. externus (rare genotype) newly discovered from New Zealand and $\mathbf{d} A$. woodi collected from Canadian bees. Images taken at a 400× magnification under light microscopy by Dr. Qing Hai Fan.

previously been used successfully to carry out a national survey of 458 hives in the UK to determine the presence and distribution of Kashmir bee virus (Ward et al. 2007a). This work demonstrates the practical application of molecular technology as a support tool for surveys and contingency management and to provide robust surveillance data on the presence or absence of honeybee pests.

The $A$. woodi real-time assay developed in this study was able to specifically amplify DNA isolated from $A$. woodi mites originating from two different geographical locations (Canada and UK). The probe and primer sequences developed were also compared to the COI sequences recently submitted for $A$. woodi from Spain and Japan, and $A$. externus from Japan, and there was a $100 \%$ match to sequences for the same gene region for A. woodi only, from both localities. It is therefore expected that the assay would work effectively for the full geographic distribution of $A$. wood $i$.

Initial experiments did show that the real-time assay was not cross-reacting with DNA isolated from a range of individual $A$. externus and A. dorsalis mites from different geographical locations or with bees known to still have these mite species on their bodies. In 2010 and 2011, when DNA was tested from bees collected as part of the New Zealand national survey for exotic pests, positive signals were obtained with the $A$. woodi real-time assay. Extensive microscopic examination of more bees from these hives ruled out the presence of $A$. wood $i$. The large amount of additional work which involved screening thousands of bees and individual Acarapis mites led to the identification of a rare population of $A$. externus from New Zealand which has 99-100 \% sequence identity in the COI gene region which is amplified by both the real-time and Evans et al. (2007) assays. Due to this high sequence similarity to $A$. woodi in this COI region, the inability to obtain the whole COI gene sequence and no other suitable gene region available for developing new specific primers (i.e. the ITS1 and ITS2 were found unsuitable for designing species-specific primers; data not shown), it was found impossible to discriminate between this rare population of $A$. externus and $A$. wood $i$ with additional molecular techniques such as high-resolution melt analysis or restriction fragment length polymorphism. Other techniques such as ELISA are not as sensitive as the real-time PCR assay and are not suitable for detection below $5 \%$ incidence (Sammataro et al. 2013). Therefore, TDM is currently considered the only method suitable for confirmation of $A$. woodi presence in positive hives, especially at low incidence. 
However, from the screening worked done, the number of bees in New Zealand which have this newly found $A$. externus genotype is thought to be small. For example, in 2011, this amounted to one to two bees in 2100 tested. In addition, based on the number of DNA extractions giving a positive signal, this suggests that only one or two bees in each of the so called 'positive hives' had this rare genotype of mite on their body. Within the mite population pulled off from 1000 bees, only 2 out of 139 gave a positive signal again, showing that only $\sim 1 \%$ of the $A$. externus population are this rare genotype. This small population of $A$. externus mites were found to be located in the neck area of the bee, as is the usual location for A. externus mites, and are perhaps an evolutionary link between $A$. externus and $A$. woodi.

Despite the cross-reaction observed with a very small percentage of genetically different A. externus mites on New Zealand bees, we have been reassured about the usefulness of the assay by additional testing done by the Department of Ecology at the Swedish University of Agricultural Sciences (Sweden). In 2010, they trialled our realtime assay as a surveillance tool to screen new imports of queen bees (Dr. E. Forsgren, personal communications). Sweden, like New Zealand, does not have tracheal mites. For the Swedish work, queen bees were pooled as $20 \times 15$ bees ( 300 bees in total). All samples were tested negative, and no false positives were observed. Later that year, a further batch of queen bees were tested (300 bees) and four of the bulked samples gave a positive PCR signal. The bees were checked using TDM, and tracheal mites were found in 1 out of 64 microscopically examined bees (Dr. E. Forsgren, personal communications). This suggests that the assay was sensitive enough to give an accurate result especially when used together with the TDM for confirmation of results.

Our bulking experiments and blind panel testing showed sensitive detection of $A$. woodi DNA from a single infested bee when mixed with 14 healthy bees. In addition, $A$. wood $i$ DNA could be detected even if that single infected bee had less than 10 mites present in its trachea. The blind panel results also showed successful detection down to a $1 \%$ infection rate. The sensitivity of detection for low infestation in a single bee is comparable to that reported in other PCR-based test methods such as Kojima et al. (2011), but this published method was applied to DNA extractions from single bees and was not tested on bulked extractions or for cross-reaction to closely related species such as $A$. dorsalis . The sensitivity of the real-time PCR assay is higher than that reported for other methods used for testing bulked bee samples such as ELISA, which is known to be unreliable when mite prevalence is below $5 \%$ (Sammataro et al. 2013).

After screening bees from the New Zealand national survey programme for exotic pests, we were able to work out that at least 900 bees bulked at a rate of 15 bees per extraction could be processed by one person within one working day $(8 \mathrm{~h})$, which is nearly three times more bees than can be processed using the TDM (estimated at approximately 350 bees/person/day). However, cost comparisons show that the cost per test with the molecular method is nearly double compared to manual screening at NZ\$ 0.76 per bee versus NZ\$ 0.42 per bee, respectively. Despite the higher cost, as more bees can be processed by one person per day, cost savings could still be made on the number of staff and staff time required to screen the bees. The cost of confirmation of positive results by TDM would be minimal, as validating molecular test results with a secondary method is already normal practice in most laboratories.

In summary, despite the cross-reaction observed with the small percentage of genetically different $A$. externus in New Zealand, the assay has been shown to be a useful tool for bee-screening programmes in New Zealand and overseas, particularly when used in conjunction with the TDM to confirm results when positive signal is obtained.

\section{ACKNOWLEDGMENTS}

We thank local and overseas beekeepers for the provision of bees and are particularly thankful to Dr. J. McMullan, Mr. M. Kempers and Mr. L. I. de Guzman for the provision of Acarapis -infested bees. We are also thankful to Dr. E. Forsgren for sharing data from their trail of our assay. 
Développement et évaluation d 'un test PCR en temps réel pour la détection d'Acarapis woodi (acarien de la trachée) chez Apis mellifera

abeille / Acari / trachée / extraction automatisée de I'ADN / ACP

Entwicklung und Überprüfung einer real-time PCR methode zum Nachweis von Acarapis woodi (Trachenmilbe) bei Apis mellifera

\section{Honigbienen / Tracheenmilbe / Acarapis / automatisierte DNA extraktion / real-time PCR}

\section{REFERENCES}

Afonina, I., Ankoudinova, I., Mills, A., Lokhov, S., Huynh, P., Mahoney, W. (2007) Primers with 5' flaps improve real-time PCR. Biotechniques 43, 770-773.

Burgher-MacLellan, K.L., Gaul, S., MacKenzie, K., Vincent, C. (2009) The use of real-time PCR to identify blueberry maggot (Diptera:Tephritidae, Rhagoletis mendax) from other Rhagoletis species and in low bush blueberry fruits (Vaccinium angustifolium ). ISHS Acta Horticulturae 810: IX International Vaccinium Symposium. March 2009.

CAPCO (1992) CAPCO note: scheduling of menthol for honey bee tracheal mite control. Canadian Association of Pesticide Control Officials-Health Canada-C92-05.

Celle, O., Blanchard, P., Olivier, V., Schurr, F., Cougoule, N., Faucon, J.-P., Ribière, M. (2008) Detection of chronic bee paralysis virus (CBPV) genome and its replicative RNA form in various hosts and possible ways of spread. Virus Res. 133, 280-284.

Chantawannakul, P., Ward, L.I., Boonham, N., Brown, M. (2006) A scientific note on the detection of honeybee viruses using real-time PCR (Taqman ${ }^{\mathbb{B}}$ ) in Varroa mites collected from a Thai honeybee (Apis mellifera) apiary. J. Invertebr. Pathol. 91, 69-73.

Chen, Y., Evans, J.D., Zhou, L., Boncristiani, H., Kimura, K., Xiao, T., Litkowski, A.M., Pettis, J.S. (2009) Asymmetrical coexistence of Nosema ceranae and Nosema apis in honey bees. J. Invertebr. Pathol. 101, 204-209.

Denmark, H.A., Cromroy, H.L., and Sanford, M.T. (2000) Honey bee tracheal mite, Acarapis woodi (Rennie) (Arachnida:Acari:Tasonemidae). DPI Entomology Circular 267. University of Florida, IFAS Extension.
Evans, J.D., Pettis, J.S., Smith, I.B. (2007) A diagnostic genetic test for the honey bee tracheal mite, Acarapis woodi. J. Apic. Res. 46, 195-197.

Kojima, Y., Yoshiyama, M., Kimura, K., Kadowaki, T. (2011) PCR-based detection of a tracheal mite of the honey bee Acarapis woodi. J. Invertebr. Pathol. 108, 135-137.

Kox, L.F.F., van den Beld, H.E., Zijlstra, C., Vierbergen, G. (2005) Real-time PCR assay for the identification of Thrips palmi . EPPO Bulletin 35, 141-148.

Navajas, M., Gutierrez, J., Lagnel, J. (1996) Mitochondrial cytochrome oxidase I in tetranychid mites: a comparison between molecular phylogeny and changes of morphological and life history traits. Bull. Ent. Res. 86, 407-417.

Pettis, J.S., Pankiw, T. (1998) Grooming behaviour by Apis mellifera L. in the presence of Acarapis woodi (Rennie) (Acari:Tasonemidae). Apidologie 29, 241253.

Sammataro, D., de Guzman, L., George, S., Ochoa, R., Otis, G. (2013) Standard methods for tracheal mite research. In: V. Dietemann, J. D. Ellis, P. Neumann (Eds), The COLOSS BEEBOOK: Volume II: Standard methods for Apis mellifera pest and pathogen research. J. Apic. Res. 52 (4): http://dx.doi.org/10.3896/ IBRA.1.52.4.20.

Schmid-Hempel, P. (1998) Parasites in social insects. Princeton University Press, Princeton, New Jersey, USA.

Tamura, K., Dudley, J., Nei, M., Kumar, S. (2007) MEGA4: Molecular evolutionary genetics analysis (MEGA) software version 4.0. Mol. Biol. Evol. 24, 1596-1599.

Ward, L.I., Waite, R., Boonham, N., Fisher, T., Pescod, K., Thompson, H., Chantawannakul, P., Brown, M. (2007a) First detection of Kashmir bee virus in the UK using real time PCR. Apidologie 38, 181-190.

Ward, L.I., Brown, M., Neumann, P., Wilkins, S., Pettis, J.S., Boonham, N. (2007b) A DNA method for screening hive debris for the presence of small hive beetle (Aethina tumida). Apidologie 38, 272-280.

Yu, D.J., Chen, Z.L., Zhang, R.J., Yin, W.Y. (2005) Real time qualitative PCR for the inspection and identification of Bactrocera philippinensis and Bactrocera occipitalis (Diptera:Tephritidae) using SYBR Green assay. The Raffles Bull. Zool. 53, 73-78.

Zheng, J., Subbotin, S.A., He, S., Gu, J., Moens, M. (2002) Molecular characterisation of some Asian isolates of Bursaphelenchus xylophilus and B. mucronatus using PCR-RFLPs and sequences of ribosomal DNA. Russ. J. Nematol. 11, 17-22. 